\title{
Cephalopod Neural Networks
}

\author{
Roddy Williamson Abdesslam Chrachri \\ School of Biological Sciences, University of Plymouth, Plymouth, UK
}

\section{Key Words}

Squid - Octopus - Statocyst - Vision · Chromatophore . Memory

\begin{abstract}
Cephalopods have arguably the largest and most complex nervous systems amongst the invertebrates; but despite the squid giant axon being one of the best studied nerve cells in neuroscience, and the availability of superb information on the morphology of some cephalopod brains, there is surprisingly little known about the operation of the neural networks that underlie the sophisticated range of behaviour these animals display. This review focuses on a few of the best studied neural networks: the giant fiber system, the chromatophore system, the statocyst system, the visual system and the learning and memory system, with a view to summarizing our current knowledge and stimulating new studies, particularly on the activities of identified central neurons, to provide a more complete understanding of networks within the cephalopod nervous system.
\end{abstract}

Copyright (C) 2004 S. Karger AG, Basel

\section{Introduction}

The coleoid cephalopods, comprising the squid, octopus and cuttlefish, have arguably the most advanced nervous systems amongst the invertebrates and certainly the most sophisticated systems within the phylum Mollusca [1-5, for reviews]. The only other extant group within the class Cephalopoda is the Nautiloids, which consist of 5 species that have retained the heavy external protective shell but have relatively simple nervous systems that presumably reflect the ancestral, more primitive form [6]. Although the nervous systems of the coleoid cephalopods are large and complex, containing up to $10^{8}$ neurons [7], the primal organization of the nervous system, with distributed ganglia, can still be discerned in the large brain in that it is divided into distinct lobes connected by neural tracts and connectives. This can be clearly seen in sections of the squid brain (fig. 1), where the lobes of the dorsal part of the brain are partially separated from those in the ventral part of the brain by the oesophagus, which passes through the brain centre.

Although the anatomy of the cephalopod nervous system (CNS) has been well described for a few species, e.g. Sepia officinalis [8], Octopus vulgaris [9], Loligo vulgaris $[10,11]$, and the giant axons of the squid are perhaps the most intensively studied and modelled neurons in the whole of neuroscience, there is much less information available on the physiological activity and connections within the cephalopod CNS. This review focuses on a few of the systems where such information is available but the need for further investigations and more detailed information, particularly physiological activity data, will be apparent throughout.

\begin{tabular}{ll}
\hline KARGER & @ 2004 S. Karger AG, Basel \\
Fax +4161306 1234-862X/04/0132-0087\$21.00/0 \\
$\begin{array}{l}\text { E-Mail karger@karger.ch } \\
\text { www.karger.com }\end{array}$ & $\begin{array}{l}\text { Accessible online at: } \\
\text { www.karger.com/nsg }\end{array}$
\end{tabular}

Prof. R. Williamson

Faculty of Science

University of Plymouth

Plymouth of PL4 8AA (UK)

Tel. +44 1752 232984, Fax +44 1752 233095, E-Mail rwilliamson@plymouth.ac.uk 


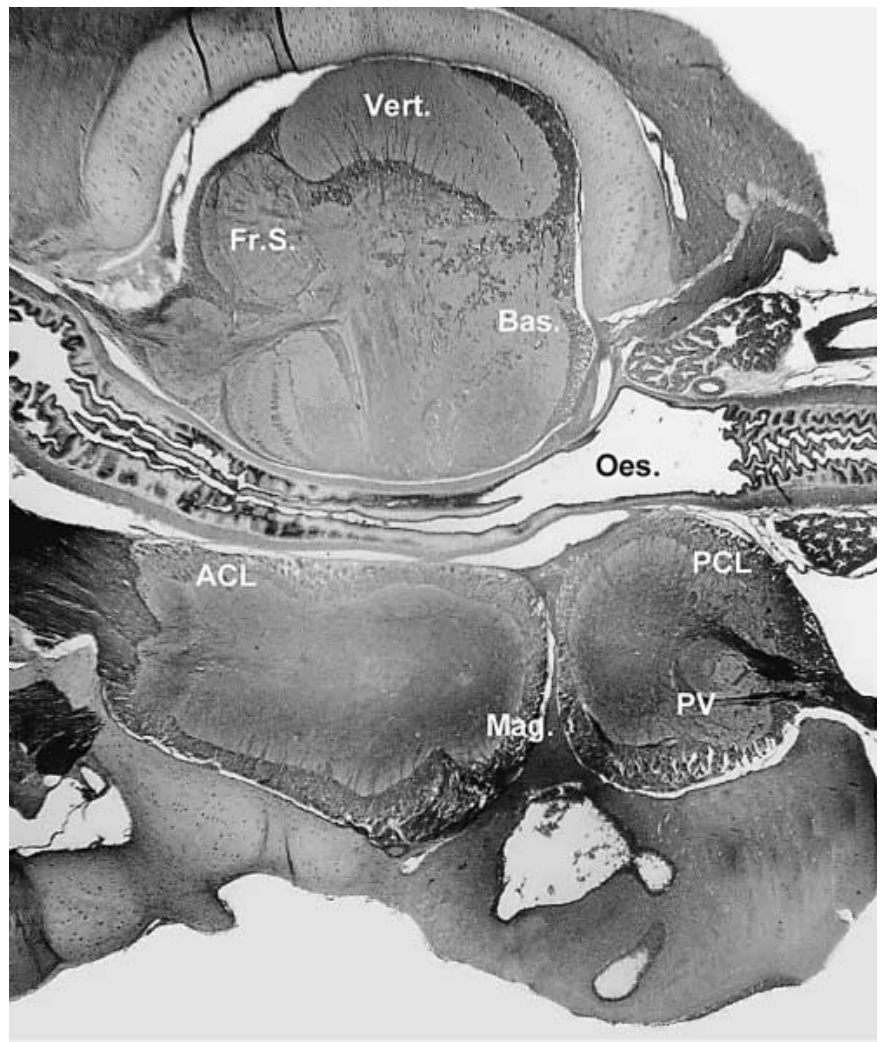

Fig. 1. Sagittal histological section through the brain of the squid, Alloteuthis subulata, showing some of the major lobes within the brain. Anterior chromatophore lobe (ACL), basal lobe (Bas.), superior frontal lobe (Fr.S.), magnocellular lobe (Mag.), oesophagus (Oes.), posterior chromatophore lobe (PCL), palliovisceral lobe (PV), and vertical lobe (Vert.).

\section{The Giant Fiber Network}

The giant fiber system is perhaps the most famous neural network system in cephalopods and comprises a chain of 3 interconnected giant nerve cells on each side of the animal. The system is present in most squid and cuttlefish, but rarely in octopuses, and is used in the jet-propelled escape response where sensory input, mainly from the eyes, results in a rapid contraction of specific muscles in the body mantle; this explosively expels water through the animal's funnel and produces a rapid backward escape movement of the animal. There are obvious parallels here with the C-start, escape response seen in some fish, driven through the Mauthner cell system [12], and the tail-flip escape response seen in some crustaceans [13].

The squid giant fiber system starts with the first order giant cell (soma up to $150 \mu \mathrm{m}$ in diameter) lying within the ventral magnocellular lobe of the brain (fig. 1, 2).
Information obtained from electrophysiological recordings from this cell [14], and from its morphology, position within the brain relative to other neuronal groups and the behavioural data showing how the system can be activated $[15,16]$, indicate that it receives major inputs from the visual and vestibular systems. Thus a perceived visual threat, or perhaps patterns of water borne vibrations detected by the statocyst or lateral line system, will provide sufficient excitation to trigger activity in the axon of the first-order giant fiber. The axon from this cell runs to the palliovisceral lobe where it crosses to the contralateral side and makes contact with its contralateral equivalent and then goes on to make synaptic contact with several second-order giant neurons (fig. 2) within the palliovisceral lobe $[17,18]$. The contact between the two first-order giants is very strong and ranges from membrane fusion in the squid, to a large, presumed electrical synapse, in the cuttlefish. This arrangement ensures that both sides of the descending giant fiber system are activated simultaneously during any escape-type response. Some of the secondorder giant fibers innervate the retractor muscles of the head and funnel but in squid a single large axon exits the brain in the pallial nerve and runs to the stellate ganglion in the mantle body, where it connects, via a 'giant synapse', to the third-order giant cells. The third-order giant cells innervate the mantle musculature via axons in the stellar nerves, the most posterior of which is generally known as 'the squid giant axon' and has been the subject of detailed physiological investigations since its description by Young $[19,17]$. The third order giant fibers are syncytial in that each axon is supported by up to 100 cell somata [20] and the resulting giant axon can be up to $1,500 \mu \mathrm{m}$ in diameter [21]. Direct electrical stimulation of the first-order giant cell, via an electrode in the magnocellular lobe [22], results in a short latency action potential in the pallial nerve (second-order cell active), followed by a spike in an ipsilateral stellar nerve (third-order cell active). The synaptic connection between the second- and third-order cells in the stellate ganglion is sometimes known as the squid giant synapse and its morphology [23], physiology and pharmacology [24, 25] have been well studied, particularly since it is feasible to place intracellular electrodes simultaneously in both the pre- and post-synaptic cells, as well as use imaging techniques to monitor changes in the concentrations of intracellular ionic species, such as calcium [26, 27]. Despite the concerted interest in this synapse, it is only recently that glutamate has been tentatively confirmed as the principal neurotransmitter, which perhaps serves as a useful reminder of how difficult it can be to firmly identify central 
neurotransmitters in invertebrates. The results of much of the work on the giant synapse have recently been reviewed by Llinas [25] and clearly show the value and promise of this network as a model system for investigating the fundamental mechanisms involved in synaptic transmission.

The giant fiber system described here is of course a simplified version of the larger neural network that controls swim-jetting behaviour in squid and cuttlefish and even many of the escape-type responses often involve non-giant fiber activity that introduces more flexibility into the behaviour and may also act to compensate for fatigue when the system is repeatedly activated [16].

\section{The Chromatophore System Control Network}

Cephalopods can very rapidly change the colour and patterning of their skin through direct neural control of skin chromatophore organs [28]. They use these skin colour changes for both inter- and intra-specific signaling and for crypsis and camouflage [29]. The system is based upon thousands of elastic sacs embedded in the skin, each filled with a choice of coloured pigments [30] and each surrounded by a set of radial muscles which when active expand the sac to display the colour within, but when inactive permit the elastic sacs to contract to a small, near invisible, specks of colour. Thus, whole areas of the skin can change colour almost instantaneously, and static or active patterns can be displayed by activation and inactivation of groups of chromatophores. Note that this cephalopod skin colour system differs from those found in some fish, amphibians, reptiles or crustaceans in that it is not controlled through the endocrine system but directly controlled by muscles that are innervated from neurons whose soma are located in the brain.

The skin patterns produced by the cephalopod chromatophore system are strongly influenced by the visual environment of the animal; thus different signaling patterns can be produced in the presence of prey, predators, potential mates or rivals, as well as when matching the background or substrate with appropriate skin camouflage patterns [29]. The importance of the visual input seems to be reflected in the central nervous control system for it appears to be organized in a strictly hierarchical fashion (fig. 3), with the highest level of control located in the optic lobes, which are also largely concerned with processing the visual input from the eyes. From the optic lobes there are projections to the intermediate control centers in the lateral basal lobes (BL) of the brain, lying on

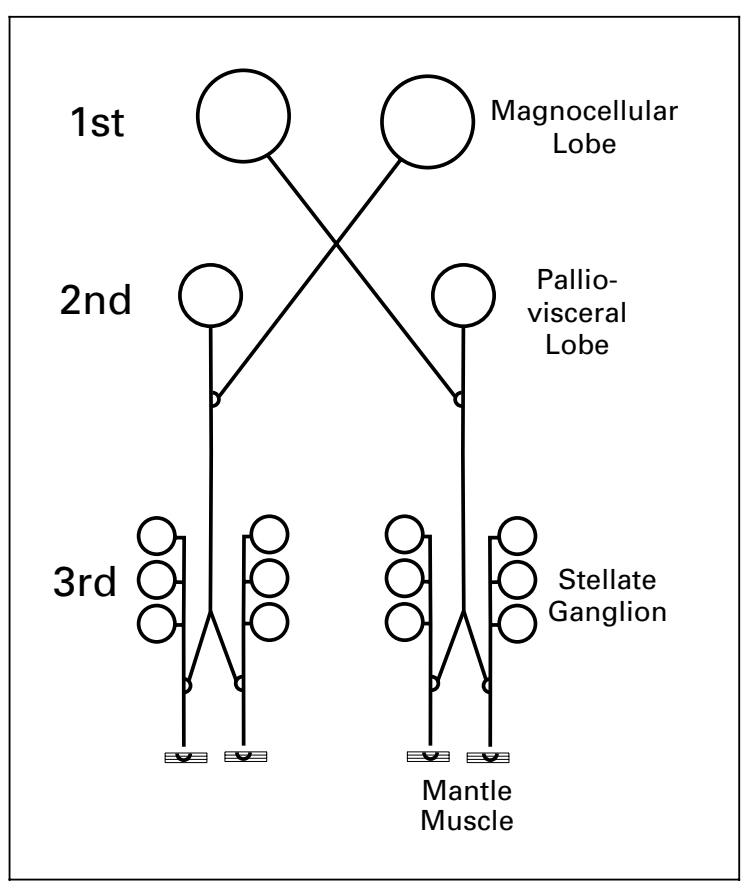

Fig. 2. Schematic representation of the giant fiber network in the squid. Right and left: first-order giant fibers have their cell bodies in the magnocellular lobe of the brain but, as their axons cross over to make synaptic contact with the second-order giant cells in the opposite side of the palliovisceral lobe, they fuse briefly together in a chiasma. The second-order giant cells send an axon out of the brain in the pallial nerve to make contact with the third-order giant neurons within the stellate ganglion. Note that the third-order giant cells are supported in a syncytial arrangement, with multiple cell bodies.

the right and left posterior side of the supra-esophageal lobe, and from here there are large fiber tracts connecting to the anterior and posterior chromatophore lobes (ACL and PCL, respectively) where the majority of the chromatophore neuronal somata are located (fig. 3). There are numerous additional tracts and interconnections to other brain regions that make up this chromatophore control network, including projections back to the optic lobes [9] and peduncle lobes (Ped.) [28]. The importance and veracity of these descending pathways in the control network have been elucidated from anatomical tracings [911, 31-34], ablation experiments [35-38], electrophysiological recordings [39, 40], and focal electrical stimulation $[31,41,42]$. Thus, electrical stimulation of areas within the optic lobes has been shown to evoke complete and recognizable skin patterns, whereas stimulation of the lower motor centers containing either the chromatophore neuron somata, or the intermediate brain nuclei that innervate the ACL and PCL, evokes only localized skin 


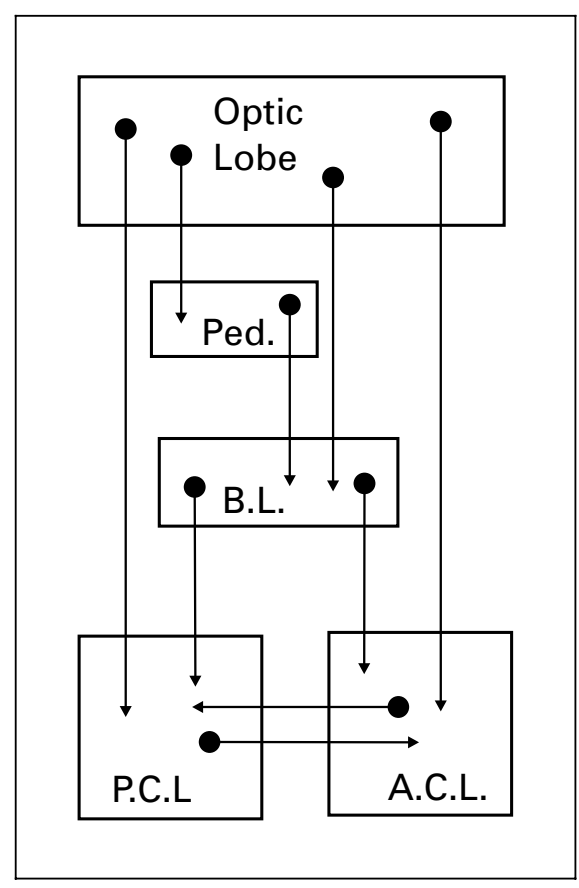

Fig. 3. Schematic representation showing the interconnections between the optic lobe, peduncle lobe (Ped.), lateral basal lobe (B.L.), and anterior and posterior chromatophore lobes (A.C.L. and P.C.L., respectively). The visual input from the eyes is processed within the optic lobes and this influences the selection of skin pattern that is then orchestrated through the peduncle and lateral basal lobes, before being activated from the motoneurons in the anterior and posterior chromatophore lobes.

colour changes or incomplete skin patterns. Although neurons within the ACL generally innervate chromatophores on the head and arms, whereas neurons in the PCL generally innervate chromatophores on the mantle, there is no clear evidence for a more detailed topographical matching of neuronal cell body location within the lobe and chromatophore location on the body [31, 43]. There is evidence however, from focal electrical stimulation of PCL motoneurons, that the chromatophores are organized into motor units of between 6 and 60 chromatophores and that individual chromatophore muscles are innervated by more than one motoneuron [44]; thus some basic skin patterns could be 'hard-wired' within the PCL or ACL and selected or mixed by the activation of specific motor units. However, more recent work [40] has shown that many PCL neurons are dye-coupled, a common indication of electrical coupling, and this could undermine the finding of Dubas et al. [43]. Finally, it should be noted that there is no known feedback from the chromatophore units to the CNS, other than through visual monitoring, and of course, not all chromatophores are visible to the animal itself. This, therefore, is an example of a complex and dynamic motor output that appears to have a limited or incomplete feedback system.

\section{The Statocyst Network}

The cephalopod statocysts are the principal sense organs detecting body orientation with respect to gravity and movements in space; they operate and perform in a manner, and at a level of sophistication, that is similar to that of the vertebrate vestibular system [45-48]. The coleoid cephalopods have two bilaterally symmetric statocysts located just ventral to the brain, and embedded in the cranial cartilage. Each of these right and left statocysts has two separate receptor systems: one which detects the linear accelerations including gravity, the macula/statoliths system, and the other which detects angular accelerations, the crista/cupula system. A significant body of morphological and electrophysiological data has been obtained from the crista/cupula and macula/statolith systems showing how they are constructed, their response characteristics and the network of interconnections that modulates and controls their operation. The angular acceleration receptor system consists of thin strips (cristae) of sensory hair cells and associated neurons which run around the inside of the statocyst approximately in the three orthogonal planes of the animal. In decapods such as squid and cuttlefish, the crista is subdivided into four segments, while in octopus, into nine segments. Each one of these crista segments (fig. 4a) carries an overlying gelatinous cupula which is attached to the tips of the mechanosensory hair cells and moves like a sail as the endolymph fluid within the statocyst cavity shifts during a head movement and thus stimulates the underlying sensory hair cells [47-49]. The sensory epithelia of the crista segments (fig. 4a) contain three main cellular elements: (1) sensory hair cells arranged in up to eight rows, and subdivided into two main types: the primary hair cells (with an axon passing towards the brain) and large and small secondary hair cells (without an axon but making synaptic contact with afferent neurons); (2) first-order afferent neurons lying close to the sensory hair cells and also comprising two sub-types, i.e. large and small primary afferent neurons, and finally (3) efferent cell inputs from the brain that innervate the sensory hair cells as well as the first-order afferent neurons [50]. Electrophysiological recordings from the statocyst have shown that the macula/statolith system responds to gravity but also to 
Fig. 4. a Schematic representation of a cross-section through the crista epithelium of the squid statocyst showing the overlying cupula, the secondary mechanosensory hair cells (dark stippled), the primary mechanosensory hair cells (light stippled), and the large and small afferent neurons (unstippled). The large efferent input to the system is not shown. b Block diagram showing the main output and input connections between the statocyst and brain in Octopus. The connections were revealed by dye tracings of the Octopus posterior crista nerve [after 67]. The arrowheads indicate afferent projections from the statocyst, whereas the filled circles indicate the sites of efferent cell bodies. Anterior basal lobe (B.A.), median basal lobe (B.Med.), dorsal magnocellular lobe (Mag.D.), ventral magnocellular lobe (Mag.V.), peduncle lobe (Ped.), anterior pedal lobe (Pe.A.), posterior pedal lobe (Pe.P.), anterior lateral pedal lobe (Pe.L.A.), posterior lateral pedal lobe (Pe.L.P.) and palliovisceral lobe (P.V.).
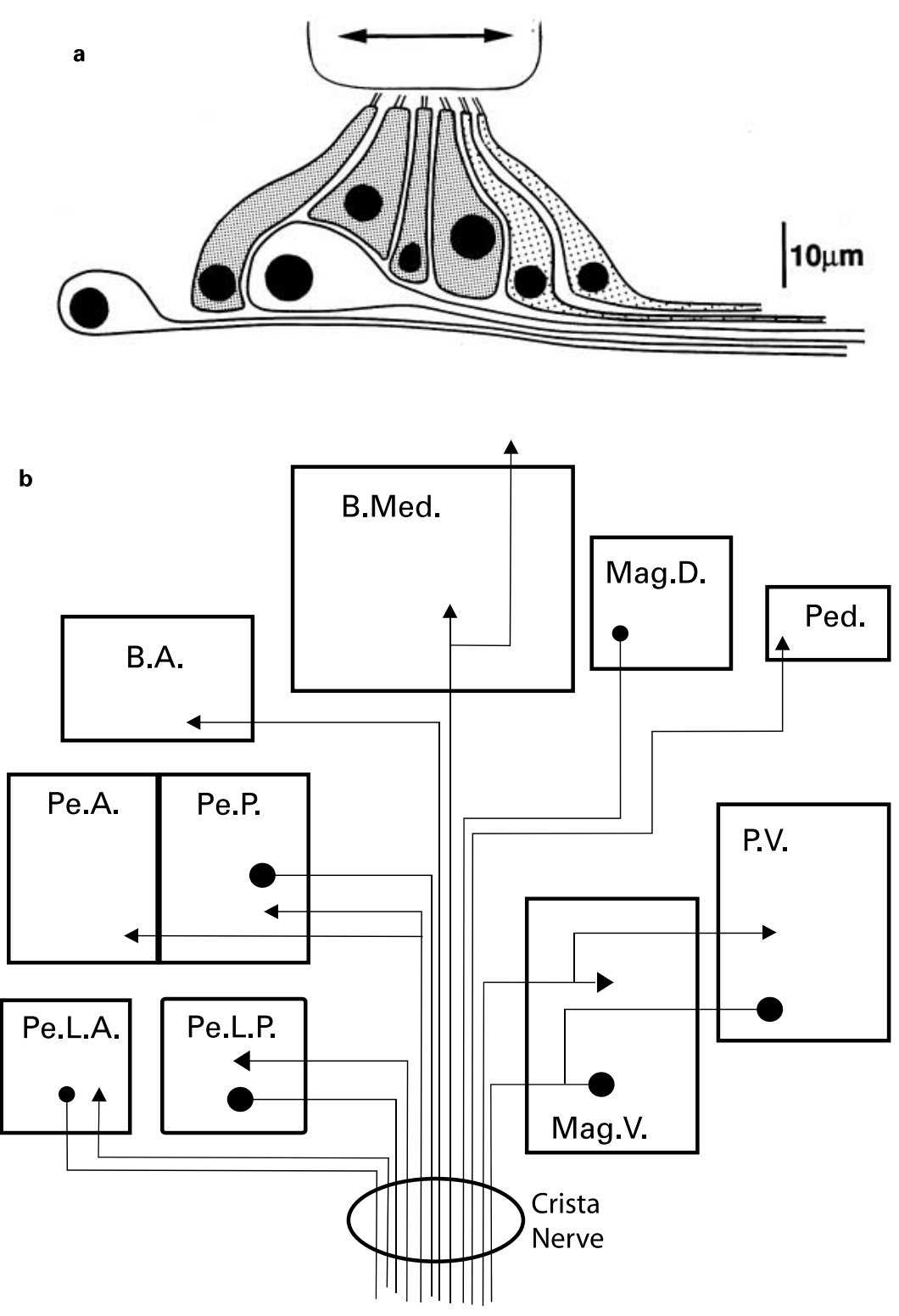

vibrations in the surrounding fluid [51] whereas the crista/cupula system acts as an angular velocity detector and has functional response characteristics similar to those of the vertebrate semicircular canal system [52]. The cellular elements within the crista epithelia, and presumably also within the sensory epithelia of the maculae, are linked by a network of synaptic interconnections and receive a very powerful efferent input from the brain; both of these operate to modulate and control the afferent information to the brain.

Cephalopod Neural Networks

\section{Synaptic Interaction between Mechanosensory Hair Cells}

Paired intracellular recording from neighboring primary sensory cells revealed that action potentials in one primary hair cell resulted in a one-for-one transmission to the other cell and this appeared either as a post-synaptic potential or as an action potential [53]. Furthermore, injection of depolarizing or hyperpolarizing currents into a primary hair cell resulted in a depolarization or hyperpolarization of the respective neighbour, demonstrating 
that they are electrically coupled and with coupling coefficients of $\leq 0.4$ for the primary sensory hair cells $[53,54]$. The secondary sensory hair cells, which are located on the outermost ventral side of the horizontal crista segments, were also shown to be coupled electrically with higher coupling coefficients of $\leq 0.6$ [55]. There was no electrical coupling found between the primary and secondary, but this was expected as these hair cells are known to be functionally polarized in the opposite directions $[49,56,57]$ and so such coupling would act to cancel out their responses. The advantage of electrical coupling between the sensory hair cells may be that it acts to improve the signal to noise ratio of the system, at the expense of reducing the high-frequency response, and thus improves the overall sensitivity.

\section{Efferent System}

The statocyst efferent cells make up a major proportion of the axons within the statocyst nerves with, on average, $75 \%$ of the axons considered to be efferent fibers [50, 57]. Individual sensory hair cells and first-order afferent neurons receive more than 15-30 efferent endings, respectively $[50,59]$ and these efferent inputs can have very powerful effects on the afferent responses. Recordings from crista cells have shown that the majority of the efferent innervation onto the hair cells and the first-order neurons is inhibitory but excitatory and mixed effects are also present $[53,56]$. Although electrical, efferent synaptic connections cannot be ruled out, many of the efferent contacts onto the sensory hair cells or the afferent neurons have been shown to be chemically mediated $[53,54]$ with morphological and histochemical evidence for the presence of two types of efferent populations with two different neurotransmitters [50,61,62]. By direct electrical stimulation of the efferents $[63,64]$, while recording the afferent output from the statocyst [51], or by pharmacological application of acetylcholine to mimic inhibitory efferent action and catecholamines to mimic excitatory efferent actions [60], it has been shown that the efferents have very powerful, but selective actions on the statocyst sensory epithelium. A further complication to the control and activity within this network is that there is evidence that the strength of the electrical coupling between the hair cells and afferent neurons may be modulated by the efferent innervation [65, unpublished data].

\section{Interactions between Hair Cells and First-Order Afferent Neurons}

Using light- and electron-microscopic studies of Octopus vulgaris, Budelmann et al. [57] demonstrated that there are two types of first-order afferent neurons, those with large somata (diameters between 20 and $35 \mu \mathrm{m}$ ) and those with small somata (diameters 5-15 $\mu \mathrm{m}$ ). They also demonstrated that the large afferent neurons probably receive much of their input from the large second-order mechanosensory hair cells while the smaller afferent neurons receive their input from the smaller second-order hair cells. However, there is a clear difference in the relationships between these two pathways in that there are roughly 4 large hair cells to each large afferent neuron, indicating a convergence of information flow, whereas there are roughly twice as many small afferent neurons compared to the number of small second-order hair cells, indicating a divergence of flow. Although the synaptic connections between the second-order sensory hair cells and the first-order neurons appear chemical, on the basis of ultrastructural data and some physiological evidence $[46,56,66]$, recent results have indicated that there may also be some electrical coupling between these cell groups [53].

Central and Efferent Projection of the Statocyst Nerves

Dye fills of the nerves from the statocysts [67] in octopus show that the axons from the primary afferent neurons and primary sensory hair cells from the cristae and maculae epithelia project directly and indirectly to numerous centers within the brain (fig. $4 b$ ) with the main areas being (1) the ipsilateral, and lateral parts of the contralateral, anterior pedal lobes, (2) the ipsilateral, and the contralateral, posterior pedal lobes, and (3) the ventral brachial and ventral magnocellular lobes. Further dye injections into the octopus brain [67] showed that the perikarya of the maculae and cristae efferents were located dorsally and ventrally in the lateral parts of the anterior palliovisceral lobe and posterolaterally in the posterior pedal lobes (fig. 4b). Some perikarya were also seen in the anterior lateral pedal lobe.

Thus the cephalopod statocyst is a sophisticated sense organ that rivals the vertebrate vestibular system in its functional characteristics and contains an intricate network of neural connections that acts to modulate and control its operation and output. In terms of investigating how such complex networks operate, the cephalopod vestibular system offers significant advantages for the experimenter over the analogous vertebrate system in that it is accessible, embedded in soft cartilage instead of bone, the afferent neurons have their somata in the periphery and hence paired recordings can be made from hair cells and their afferents, and there is a very large efferent innervation $(70 \%$ of the fibers in the nerve compared with $8-18 \%$ in vertebrates) with powerful and diverse effects. 


\section{The Visual System}

Cephalopods are highly visual predators utilizing a pair of large, elaborate eyes that are often cited as a textbook case of convergent evolution because of their close parallels with vertebrate eyes [2]. Both groups have single chamber, camera type eyes, with focusing lenses, variable sized pupils, large retina with foveal areas where the receptor cells are more densely packed to increase acuity, and a screening pigment that migrates outwards under high light intensities [7, 68-71]. There are nevertheless distinct differences in the cephalopod system in that: (1) the photoreceptors are of the invertebrate, rhabdomeric type [70], with each photoreceptor having an axon that exits at the back of the retina and so there is no blind spot in the cephalopod retina; (2) only rod-like photoreceptors are present in the cephalopod retina and these appear sensitive to a narrow range of light wavelengths and so vision is almost exclusively monochromatic [but see 72]; (3) polarized vision is common in cephalopods [73, 74]; (4) the retina contains only the photoreceptors and the terminals of an efferent projection and so visual processing, as found in the vertebrate retina, is most likely relocated to the optic lobe region of the brain $[75,76]$.

The cephalopod optic lobes are large CNS areas, lying just behind the eyes, which receive the photoreceptor axons from the eyes and are connected to the rest of the brain and motor centers through large optic tracts. It is within these optic lobes that the major processing of visual information is believed to occur [e.g. 9, 77-79]. Each of the paired optic lobes has two anatomically distinct areas; an outer cortex and a central medulla [e.g. 9, $31,80,81]$. The outer cortex, also called the 'retina profunda' or 'deep retina' [8] due to its similarity with the ganglionic layer of the vertebrate retina, is where most of the processing and classification of the visual inputs from the retina is thought to occur [81]. This cortex is mainly composed of two layers of cell somata; the outer and inner granule cell layers that are separated by a complex neuropil zone, the plexiform zone [10, 31]. In octopus, the outer granule layer comprises mainly amacrine neurons lacking axons, but in decapods, cells with axons running towards the medulla have also been reported $[10,82]$. By contrast, the inner granule cell layer in both octopods and decapods has a more varied cellular composition, containing four main cell types: reverse amacrines and centrifugal cells as well as the more centrally occurring centripetal and multipolar neurons $[9,10,81,82]$.

The much larger central medulla area is considered as a visuomotor region which also serves as a memory centre
$[45,82]$. The medulla consists of numerous clusters of cell bodies (or cell islands) separated by tracts of fibers (neuropil), containing both axons and dendrites. The cell islands contain many large unipolar cells that branch into numerous, presumably dendritic, branches, one of which forms an axon which passes towards the optic tract. This tract provides the communication between the optic lobe and other areas of the CNS $[9,10,83]$.

\section{Synaptic Interactions within the Visual System of Cephalopods}

Although the cephalopod retina contains only photoreceptors and supporting cells, the photoreceptors have basal processes that could permit interactions between photoreceptors $[75,76]$. This view is supported by single unit, extracellular recordings from the photoreceptor axons that indicate that the retinal outputs are already organized into 'on-off' receptive fields [84], presumably through a network of direct photoreceptor to photoreceptor interactions. In addition, the efferent input to the retina from the brain has been shown to modify the retinal responses, again presumably through synaptic connections with the photoreceptors within the retina [76].

Within the optic lobe, the retinal photoreceptors terminate mainly in the plexiform zone of the outer cortex [9, 10] and are retinotopically mapped onto the lobe [85]. Morphological studies indicate that the photoreceptors make synaptic contact with the amacrine neurons located in the outer and inner granule cell layers [86] and this is supported by field potential recordings showing synaptic responses within the plexiform zone $2-6 \mathrm{~ms}$ after optic nerve stimulation [87]. The neurotransmitter employed by the photoreceptors is likely to be acetylcholine [88, 89]. Using a brain slice preparation, Chrachri and Williamson [90] have recently shown that stimulation of an optic nerve bundle in cuttlefish evokes excitatory postsynaptic currents in amacrine neurons located in the inner granule cell layer, supporting the view that these neurons are in direct synaptic contact with the retinal photoreceptors. A class of centripetally running neurons, with somata in the inner granule cell layer, has their dendritic fields organized in specific planes and directions within the plexiform zone such that they could extract orientation information from the visual field $[9,10,81]$. The axons of these centripetal neurons pass into the medulla and physiological recordings of their activity [91] support the view that these are second order visual neurons. Within the medulla, Young [9] identified radial columns of cells that make lateral interactions as they proceed deeper into the medulla and he proposed that these make contact with feature- 


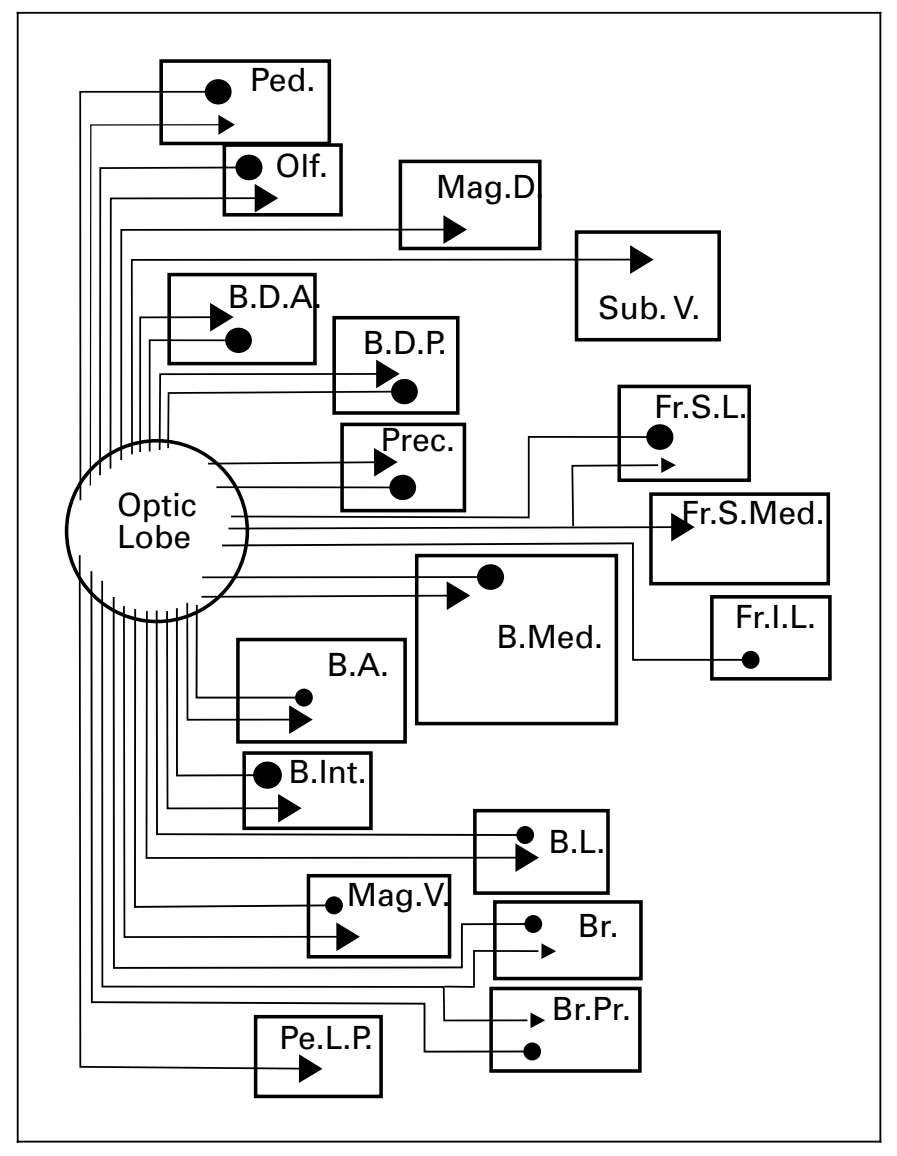

Fig. 5. Block diagram showing the main output and input connections between the optic lobes and other brain regions in Octopus. The connections were revealed by dye injections and tracings from the optic lobes [after 67,83]. The arrowheads indicate afferent projections from the optic lobe, whereas the filled circles indicate the sites of efferent cell bodies. Anterior basal lobe (B.A.), anterior dorsal basal lobe (B.D.A.), posterior dorsal basal lobe (B.D.P.), interbasal lobe (B.Int.), lateral basal lobe (B.L.), median basal lobe (B.Med.), brachial lobe (Br.), prebrachial lobe (Br.Pr.), lateral inferior frontal lobe (Fr.I.L.), lateral superior frontal lobe (Fr.S.L.), median superior frontal lobe (Fr.S.Med.), dorsal magnocellular lobe (Mag.D.), ventral magnocellular lobe (Mag.V.), olfactory lobe (Olf.), peduncle lobe (Ped.), posterior lateral pedal lobe (Pe.L.P.), precommissural lobe (Prec.) and subvertical lobe (Sub.V).

detecting neurons. As yet there is no physiological evidence to support this hypothesis although Chrachri and Williamson [unpubl.] have recorded from neurons within the medulla that responded with volleys of EPSCs to stimulation of the optic nerve photoreceptor axons.

The efferent neurons that innervate the retina have their somata in the inner granule cell layer of the optic lobe and could modify the photoreceptor responses through action on the cell membrane potentials, the elec- trical coupling between cells, and through changes in the screening pigment location [71, 92]. Intracellular recordings from these efferent neurons show that they receive short latency inputs immediately after stimulation of the photoreceptor axon bundles, implying that there are direct connections between the afferent and efferent networks [93; Chrachri and Williamson, unpubl.].

\section{Central Connections of the Optic Lobes}

The output and input pathways between the optic lobes and the rest of the brain have been studied by a variety of histological and dye tracing techniques $[9,67,83]$ and a large number of both direct and indirect projections were identified. A summary of the direct, ipsilateral pathways from the octopus optic lobe to the central brain is shown in figure 5 . In the main, the optic lobe output fibers project to various divisions of the prebrachial, brachial, pedal, magnocellular, basal, subvertical, peduncle, olfactory and contralateral optic lobes. Additional smaller projections have also been observed, as well as numerous possible indirect projections. However, without supporting evidence, such as physiological recording or stimulation data, these are difficult to interpret. Inputs to the optic lobes from the central brain arise from many of the main output areas identified above (fig. 5) as well as from the frontal and inferior frontal lobes. The peduncle and olfactory lobes located on the optic tract [94], the former sometimes known as the cephalopod cerebellum [95], seem particularly well situated to play a major role in the processing of visual information. Similarly, the magnocellular lobe, which is involved in the escape behaviour, and the vertical lobe, which has been shown to be involved with both visual and tactile memory [9], both appear strong candidates for further physiological studies of visual evoked activity.

\section{Networks Involved in Learning and Memory}

Learning and memory capabilities are well developed in cephalopods and there is a substantial body of work describing their performance in various forms of shortand long-term memory tasks [e.g. 28, 96-99] as well as in tests of habituation, conditioning, associative learning, discrimination learning, and even social learning [e.g. 9, 15, 100-103]. These reports show that cephalopods can rival the accomplishments of many vertebrates in such tasks [e.g. 104]. However, in experiments testing sensory discrimination, where partial brain ablations were also performed, it was found that there appear to be two quite 
distinct central memory systems present, one for visual tasks and another for tactile/taste tasks [105-107] and that: (1) tactile learning is mostly associated with the subfrontal lobes; (2) visual learning is associated with the optic lobes; (3) damage to the vertical and sub-frontal lobes does not affect movement nor posture, but is specifically disruptive to learning, and finally (4) lesions to the vertical lobe affect both visual and tactile learning systems [for reviews, see 9, 11, 32, 108, 109].

\section{The Visual Memory System}

The store for visual memory appears to be associated with the optic lobes, but there is an important ancillary circuit involving the median superior frontal lobes and the vertical lobe [99, 110-113]. Experimental evidence indicates that visual memories are laid down bilaterally, although normally an octopus attacks with the prey image in the visual field of a single eye, implying that the memory established in one optic lobe must be transferred to the contralateral optic lobe via the central, large commissure. Interruption of this commissure prior to training abolishes transfer while section afterwards does not [114].

The discrimination of the visual image is thought to take place in the optic lobe cortex via the pathway described above; i.e. the photoreceptor cells synapse with second-order neurons in the cortex of the optic lobe [9] and these second-order neurons (the amacrine and centripetal neurons) have dendritic fields [10] arranged to best extract particular aspects of the visual input (such as object orientation) and match this information with respect to body orientation, as given by the gravity detecting system in the statocysts. Axons from the second order neurons pass to the central medulla of the optic lobe where they combine with the inputs from other neurons in the visual pathway to form 'classifying cells'; this information is then transferred to other CNS areas where an appropriate response to the visual cue is elicited [99]. It has been postulated that visual inputs related to a potential predator, and thus likely to evoke an escape response, are communicated via identified pathways to the magnocellular lobes, for these are involved in direct motor responses, whereas visual inputs related to potential prey items, and thus likely to evoke an attack sequence, are communicated via separate pathways to the peduncle and basal lobes, which are involved in orchestrating more complex motor sequences [99].

Numerous other experiments have confirmed that visual discrimination tasks are impaired by lesions in the vertical lobe system $[113,115]$ and that if part of this lobe is removed, then the accuracy of the memory is propor- tionately reduced. Similar results have also been obtained after manipulations of the optic lobes [111]; however, animals without a peduncle lobe are still capable of learning visual discrimination tasks, but the execution of the responses is impaired [94]. Impairment of visual discrimination tasks can also be achieved through biochemical disruption for Robertson et al. [116] have shown that inhibition of the nitric-oxide synthase system blocks visual learning.

\section{The Tactile Memory System}

Cephalopods possess a separate memory system for touch learning [117]. This system takes information from the arms and numerous sensory receptors associated with the arm suckers [e.g. 118] and ensures that the arms draw food objects towards the mouth and reject non-food objects [119]. A clear example of this second system is the ability to learn to discriminate between rough and smooth objects; this is not a visual task, for the test objects used in these experiments could not be visually discriminated, and the task could be learned in the absence of the optic lobes (a necessary lobe for visual task learning), but could not be learned in the absence of the sub-frontal lobes [117]. Although this sub-frontal lobe contains the major tactile memory, the vertical lobe has also been shown to be involved in tactile learning $[99,117,120]$. As with the visual system, the brain systems involved in tactile learning can be disrupted by the administration of blockers of protein synthesis or nitric oxide synthase activity [116, 121].

Since the vertical lobe participates in both types of learning, it would be of considerable interest to see whether the same populations of neurons are involved in both, or whether there are separate pools for each. Physiological experiments in progress indicate that the octopus vertical lobe can exhibit long-term potentiation (LTP), a phenomenon closely associated with vertebrate memory, and it may be that the early analogies drawn between the vertebrate hippocampus and the cephalopod vertical lobe on the basis of structural similarities [e.g. 95] can be confirmed by physiological and behavioural experiments.

With regard to the neurotransmitters implicated in learning and memory, there is already substantial evidence for the involvement of cholinergic system in both vertebrates [122-124] and invertebrates [125-127]. Similarly, within the cephalopods, there is biochemical and pharmacological information on the distribution of acetylcholine within the CNS $[128,129]$ and clear evidence that disruption of the cholinergic systems in the higher CNS centers, such as in the vertical and frontal lobes, 
interferes with both learned behaviours [130] and memory recall [131]. There is of course extensive evidence for the presence of almost all of the other major neurotransmitters and neuromodulators within the cephalopods CNS [for reviews see 31,128 ], but apart from acetylcholine and nitric oxide there is little published work linking these specifically to memory and learning.

\section{Conclusion}

This short review of neural networks within the cephalopods has focused on just a few of the systems where there is complementary morphological, physiological and behavioural data that provide a basis for understanding the function and operation of the networks. There are a whole variety of other cephalopod systems, such as the control of the arms [132], the olfactory system [133], the oculomotor system [134], where there is already a considerable body of knowledge that will soon enable us to establish more completely how these systems operate and integrate into the overall behaviour of the animal. The cephalopods are a fascinating group of animals, capable of producing a wide repertoire of behaviour and, as this review has indicated, they provide excellent invertebrate models for the goal of understanding behaviour in terms of the operations of the underlying neural substrate.

\section{References}

1 Mangold-Wirz K: Biologie des Céphalopods benthiques et nectoniques de la Mer Catalane. Vie Milieu Suppl 1963;13:1-285.

2 Packard A: Cephalopod and fish: the limits of convergence. Biol Rev 1972;47:241-307.

3 Moynihan M, Rodaniche AF: The behaviour and natural history of the Caribbean reef squid. Sepioteuthis sepioidea. Adv Ethol 1982;25:1150.

4 Aronson RB: Ecology, paleobiology and evolutionary constraint in the octopus. Bull Mar Sci 1991;49:245-255.

5 Nixon M, Young JZ: The Brains and Lives of Cephalopods. Oxford, Oxford University Press, 2003.

6 Young JZ: The central nervous system of Nautilus. Phil Trans R Soc Lond Biol 1965;249:125.

7 Young JZ: The number and sizes of nerve cells in Octopus. Proc Zool Soc Lond 1963;140:229_ 254.

8 Cajal Y Ramon: Contribution al conocimiento de la retina y centros opticos de los cefalopodos. Trab Lab Invest Biol Univ Madr 1917;15: $1-82$.

9 Young JZ: The Anatomy of the Nervous System of Octopus vulgaris. Oxford, Clarendon Press, 1971.

10 Young JZ: The central nervous system of $\mathrm{Lo}$ ligo. I. The optic lobe. Phil Trans R Soc Lond [B] 1974;267:263-302.

11 Young JZ: The nervous system of Loligo. II. Phil Trans R Soc Lond [B] 1976;274:101-167.

12 Eaton RC, Bombardieri RA, Meyer DL: The Mauthner-initiated startle response in teleost fish. J Exp Biol 1977;66:65-81.

13 Zucker RS: Crayfish escape behavior and central synapses. I. Neural circuit exciting lateral giant fiber. J Neurophysiol 1972;35:599-620.
14 Pozzo-Miller LD, Moreira JE, Llinas RR: The first-order giant neurons of the giant fiber system in the squid: Electrophysiological and ultrastructural observations. J Neurocytol 1998; 27:419-429.

15 Boyle PR: Neural control of cephalopod behaviour; in Willows AOD (ed): The Mollusca. New York, Academic Press, 1986, vol 9, part 2, pp 1-97.

16 Otis, T, Gilly WF: Jet-propelled escape in the squid Loligo opalescens: Concerted control by giant and non-giant motor axon pathways. Proc Natl Acad Sci USA 1990;87:2911-2915.

17 Young JZ: Fused neurons and synaptic contacts in the giant nerve fibers of cephalopods. Phil Trans R Soc Lond [B] 1939;229:465-503.

18 Martin R: The structural organization of the intracerebral giant fibre system of cephalopods: The chiasma of the first order giant axons. $\mathrm{Z}$ Zellforsch Mikrosk Anat 1969;97:50-68.

19 Young JZ: Structure of nerve fibers and synapses in some invertebrates. Cold Spring Harbor Symp Quant Biol 1936;4:1-6.

20 Martin R, Miledi R: The form and dimensions of the giant synapse of squids. Proc R Soc Lond Biol 1986;312:355-377.

21 Villegas GM, Villegas R: Squid axon ultrastructure; in Baker PF (ed): Current Topics in Membrane Transport, New York, Academic Press, 1984, vol 22, pp 3-37.

22 Gilly WF, Hopkins B, Mackie GO: Development of giant motor axons and neural control of escape responses in squid embryo and hatchlings. Biol Bull 1991;180:209-220.

23 Young JZ: The giant fiber synapse of Loligo. Brain Res 1973;57:457-460.

24 Katz B, Miledi R: Input-output relations of a single synapse. Nature 1966;212:1242-1245.

25 Llinas RR: The Squid Giant Synapse. New York, Oxford University Press, 1999.

26 Miledi R, Slater CR: The action of calcium on neuronal synapses in the squid. J Physiol (Lond) 1966;184:473-498.
27 Llinas RR, Sugimori M, Silver RB: Time resolved calcium microdomains and synaptic transmission. J Physiol (Paris) 1995;89:77-81.

28 Messenger JB: Cephalopod chromatophores: Neurobiology and natural history. Biol Rev 2001;76:473-528.

29 Hanlon RT, Messenger JB: Cephalopod Behaviour. Cambridge, Cambridge University Press, 1996.

30 Florey E: Nervous control and spontaneous activity of the chromatophores of a cephalopod Loligo opalescens. Comp Biochem Physiol 1966;8:305-324.

31 Boycott BB: The functional organization of the brain of the cuttlefish Sepia officinalis. Proc R Soc Lond [B] 1961;153:503-534.

32 Young JZ: The diameters of the fibres of the peripheral nerves of octopus. Proc R Soc Lond [B] 1965c;162:47-79.

33 Young JZ: The nervous system of Loligo. V. The vertical lobe complex. Phil Trans R Soc 1979;285:311-354.

34 Messenger JB: The nervous system of Loligo. IV. The peduncle and olfactory lobes. Phil Trans R Soc Lond [B] 1979;285:275-309.

35 Messenger JB: The effects on locomotion of lesions to the visuo-motor system in Octopus. Proc R Soc Lond [B] 1967;167:252-281.

36 Froesch D: The synaptic profiles in the posterior chromatophore lobe of the Octopus brain: A study in normal and degenerated tissue. Brain Res 1972;48:1-9.

37 Andrews PLR, Messenger JB, Tansey EM: The chromatic and motor effects of neurotransmitter injection in intact and brain lesioned Octopus. J Mar Biol Assoc UK 1983;63:355-370.

38 Packard A: Through the looking-glass of cephalopod colour patterns: Behavioural brain research in naturalistic and semi-naturalistic settings; in Alleva E, Fasolo A, Lipp H P, Nadel L, Ricce L (eds): Netherlands, Kluver Academic Press, 1995, pp 105-130. 
39 Mislin H, Riesterer L, Schroeder D: Die Aktionspotentiale (EEG) der visceralen Chromatophorenzentren bei Cephalopoden (Octopus vulgaris). Helv Physiol Pharmac Acta 1954;12: C85.

40 Miyan JA, Messenger JB: Intracellular recordings from the chromatophore lobes of Octopus; in Abbott NJ, Williamson R, Maddock L (eds): Cephalopod Neurobiology. Oxford, Oxford University Press, 1995, pp 415-429.

41 Chichery R, Chanelet J: Motor and behavioral responses obtained by stimulation with chronic electrodes of the optic lobe of Sepia officinalis. Brain Res 1976;105:525-532.

42 Chichery R, Chanelet J: Motor responses obtained by stimulation of the peduncle lobe of Sepia officinalis in chronic experiments. Brain Res 1978;150:188-193.

43 Dubas F, Hanlon RT, Ferguson GP, Pinsker HM: Localization and stimulation of chromatophore motoneurones in the brain of the squid, Lolliguncula brevis. J Exp Biol 1986; 121:1-25.

44 Dubas F, Boyle PR: Chromatophore motor units in Eledone cirrhosa (Cephalopoda: Octopoda). J Exp Biol 1985;117:415-431.

45 Young JZ: The statocyst of Octopus vulgaris. Proc R Soc Lond 1960;152:3-29.

46 Stephen PR, Young JZ: The statocyst of Loligo. J Zool Lond 1982;197:241-266.

47 Budelmann BU: Morphological diversity of equilibrium receptor systems in aquatic invertebrates; in Atema J, Fay RR, Popper AN Tavolga WN (eds): Sensory Biology of Aquatic Animals. New York, Springer-Verlag, 1988, pp 757-782.

48 Budelmann BU: The statocysts of squid; in Gilbert DL, Adelman WJ, Arnold JM (eds): Squid as Experimental Animals. New York, Plenum Press, 1990, pp 421-442.

49 Budelmann BU: Structure and function of the angular acceleration receptor systems in the statocysts of cephalopods. Symp Zool Soc Lond 1977;38:309-324

50 Budelmann BU, Williamson R, Auerbach U: Structure and function of the angular acceleration receptor system of the statocyst of Octopus with special reference to its efferent innervation; in Graham MD, Kemmink JL (eds): Neurophysiologic and Clinical Research: The Vestibular System. New York, Raven, 1987, pp 165-168.

51 Williamson R: Vibration sensitivity in the statocyst of the northern octopus, Eledone cirrosa. J Exp Biol 1988;134:451-454.

52 Williamson R, Budelmann BU: The response of the Octopus angular acceleration receptor system to sinusoidal stimulation. J Comp Physiol [A] 1985;156:403-412.

53 Chrachri A, Williamson R: Synaptic interactions between crista hair cells in the statocyst of the squid, Alloteuthis subulata. J Neurophysiol 1998;80:656-666.

54 Chrachri A, Williamson R: Electrical coupling between primary hair cells in the statocyst of the squid, Alloteuthis subulata. Neurosci Lett 1993; 161:227-231.
55 Williamson R: Electrical coupling between secondary hair cells in the statocyst of squid Alloteuthis subulata. Brain Res 1989;486:67-72.

56 Williamson R: Secondary hair cells and afferent neurones in the squid statocyst receive both inhibitory and excitatory efferent inputs. $\mathbf{J}$ Comp Physiol [A] 1989;165:847-860.

57 Budelmann BU, Sachse M, Staudigl M: The angular acceleration receptor system of Octopus vulgaris: Morphometry, ultrastructure, and neuronal and synaptic organization. Phil Trans R Soc [B] 1987;315:305-343.

58 Williamson R: The responses of primary and secondary sensory hair cells in the squid statocyst to mechanical stimulation. J Comp Physiol [A] 1990;167:655-664.

59 Colmers WF: The central afferent and efferent organization of the gravity receptor system of the statocyst of Octopus vulgaris. Neuroscience 1982;7:461-476.

60 Budelmann BU, Young JZ: The statocyst-oculomotor system of Octopus vulgaris: Eye muscle, eye muscle nerves, statocyst nerves, and the oculomotor centre in the central nervous system. Phil Trans R Soc Lond [B] 1984;306:159189.

61 Auerbach B, Budelmann BU: Evidence for acetylcholine as a neurotransmitter in the statocyst of Octopus vulgaris. Cell Tissue Res 1986;243: 429-436.

62 Budelmann BU, Bonn U: Histochemical evidence for catecholamines as neurotransmitters in the statocyst of Octopus vulgaris. Cell Tissue Res 1982;227:475-483.

63 Williamson R: Efferent influences on the afferent activity from the Octopus angular acceleration receptor system. J Exp Biol 1985;119:251264.

64 Williamson R: Efferent activity in the Octopus statocyst nerves. J Comp Physiol [A] 1986;158: 125-132.

65 Williamson R, Chrachri A: The efferent system in cephalopod statocysts. Biomed Res 1994;15: $51-56$.

$66 \mathrm{Tu}$ Y, Budelmann BU: The effect of $L$-glutamate on the afferent resting activity in the cephalopod statocyst. Brain Res 1994;642:4758.

67 Plän T: Functional neuroanatomy of sensorymotor lobes of the brain of Octopus vulgaris; PhD Thesis, University of Regensburg, 1987, p 163.

68 Young JZ: The retina of cephalopods and its degeneration after optic nerve section. Phil Trans R Soc Lond [B] 1962;245:1-18.

69 Budelmann BU: Cephalopoda; in Harrison W, Kohn AJ (eds): Microscopic Anatomy of Invertebrates, New York, Wiley-Liss, 1997, vol 6A, Mollusca, part II, pp 119-414.

70 Saibil HR: Structure and function of the squid eye; in Gilbert DL, Adelman WJ, Arnold JM (eds); Squid as Experimental Animals. London, Plenum Press, 1990, pp 371-397.

71 Gleadall IG, Ohtsu K, Gleadall E, Tsukahara $\mathrm{Y}$ : Screening-pigment migration in the Octopus retina includes control by dopaminergic efferents. J Exp Biol 1993;185:1-16.
72 Seidou M, Sugahara M, Uchiyama H, Yoshihara K, Kito Y: On the three visual pigments in the retina of the firefly squid, Watasenia scintillans. J Comp Physiol [A] 1990;166:769_ 773.

73 Moody MF, Parriss JR: The visual system of Octopus: Discrimination of polarized light by Octopus. Nature 1960;186:839-840.

74 Shashar N, Rutledge PS, Cronin TW: Polarization vision in cuttlefish: A concealed communication channel? J Exp Biol 1996;199:20772084.

75 Yamamoto T, Tasaki K, Sugawara Y, Tonosaki A: The fine structure of octopus retina. J Cell Biol 1965;25:345-359.

76 Yamamoto M, Takasu N: Membrane-particles and gap-junctions in the retinas of 2 species of cephalopods, Octopus ocellatus and Sepiola japonica. Cell Tissue Res 1984;237:209-218.

77 Messenger JB: Comparative physiology of vision in mollusks; in Autrum H (ed): Comparative Physiology and Evolution of Vision in Invertebrates. Handbook of Sensory Physiology. Berlin, Springer, 1981, vol VII/6C, pp 93200.

78 Messenger JB: Photoreception and vision in cephalopods; in Cronly-Dillon JR, Gregory RL (eds): Evolution of the Eye and Visual System. London, McMillan, 1991, pp 364-397.

79 Bullock TH, Budelmann BU: Sensory evoked potentials in unanesthetized unrestrained cuttlefish: A new preparation for brain physiology in cephalopods. J Comp Physiol [A] 1991;168: 141-150.

80 von Lenhossék M: Zur Kenntnis der Netzhaut der Cephalopoden. Z Wiss Zool 1894;58:636660.

81 Young JZ: The optic lobes of Octopus vulgaris. Phil Trans R Soc Lond [B] 1962;276:19-58.

82 Haghighat N, Cohen RS, Pappas GD: Fine structure of squid (Loligo pealei) optic lobe synapses. Neuroscience 1984;13:527-546.

83 Saidel WM: Connections of the octopus optic lobe: an HRP study. J Comp Neurol 1982;206: 346-358.

84 Hartline PH, Lange GD: Optic nerve responses to visual stimuli in squid. J Comp Physiol 1974;93:37-54.

85 Saidel WM: Relationship between photoreceptor terminations and centrifugal neurons in the optic lobe of octopus. Cell Tissue Res 1979; 204:463-472.

86 Case NM, Gray EG, Young JZ: Ultrastructure and synaptic relations in the optic lobe of the brain of Eledone and Octopus. J Ultrastruct Res 1972;39:115-123.

87 Williamson R, Ichikawa M, Matsumoto G: Neuronal circuits in cephalopod vision. Neth $\mathrm{J}$ Zoo 1994;44:272-281.

88 Rosenberg P, Detbarn WD, Brazin M: Acetylcholine and choline acetylase in squid giant axon, ganglia and retina. Nature 1966;210: 858-859.

89 Gray EG: A note on the synaptic structure of the retina of Octopus vulgaris. J Cell Sci 1970;7: 203-215. 
90 Chrachri A, Williamson R: Analysis of spontaneous EPSCs and IPSCs in the amacrine neurons of the optic lobe of cuttlefish and their modulation by FMRF-amide. Comp Biochem Physiol A 2003;134:S78.

91 Hussey DA: Morphology and electrophysiology of retinal photoreceptor terminations in the octopus (Eledone cirrosa) optic lobe; $\mathrm{PhD}$ Thesis, University of Plymouth, 1999, p 320.

92 Suzuki H, Tasaki K: Inhibitory retinal efferent from dopaminergic cells in the optic lobe of the Octopus. Vision Res 1983;23:451457.

93 Patterson JA, Silver SC: Afferent and efferent components of Octopus retina. J Comp Physiol [A] 1983;151:381-387.

94 Messenger JB: The peduncle lobe: A visuomotor center in Octopus. Proc R Soc Lond [B] 1967;167:225-251.

95 Hobbs MJ, Young JZ: A cephalopod cerebellum. Brain Res 1973;55:424-430.

96 Wells MJ: Short-term learning and interocular transfer in detour experiments with octopuses. J Exp Biol 1967;47:393-408

97 Sanders GD: The cephalopods; in Corning WC, Dyal JA, Willows AOD (eds): Invertebrate Learning. New York, Plenum Press, 1975, pp 1-101.

98 Young JZ: Programs of the Brain. London, Oxford University Press, 1978.

99 Young JZ: Computation in the learning system of cephalopods. Biol Bull MBL, Woods Hole 1991;180:200-208.

100 Mackintosh NJ, Mackintosh J: Performance of octopus over a series of reversals of a simultaneous discrimination. Anim Behav 1964; 12:321-324.

101 Wells MJ: Octopus: Physiology and Behaviour of an Advanced Invertebrate. London, Chapman \& Hall, 1978, pp 217-245.

102 Fiorito G, Scotto P: Observational learning in Octopus vulgaris. Science 1992;256:545-547.

103 Moriyama T, Gunji YP: Autonomous learning in maze solution by Octopus. Ethology 1997;103:499-513.

104 Young JZ: Some comparisons between the nervous system of cephalopod and mammals; in Wiersma CAG (ed): Invertebrate Nervous Systems. Chicago, Chicago University Press, 1967, pp 353-362.

105 Young JZ: Paired centres for the control of attack by Octopus. Proc R Soc [B] 1964;159: 565-588.
106 Young JZ: The Memory System of the Brain. Oxford, Oxford University Press, 1966.

107 Wells MJ: A location for learning; in Bellairs R, Gray EG (eds): Essays on the Nervous System. Oxford, Clarendon, 1974, pp 407-430.

108 Young JZ: The nervous system of Loligo. III. Phil Trans R Soc Lond [B] 1977;276:351398.

109 Messenger JB: The eyes and skin of Octopus: Compensating for sensory deficiencies. Endeavour 1979;3:92-98.

110 Boycott BB, Young JZ: A memory system in Octopus vulgaris Lamarck. Proc R Soc Lond [B] 1955;143:449-480.

111 Boycott BB, Young JZ: Effect of interference with the vertical lobe on visual discrimination in Octopus vulgaris Lamarck. Proc R Soc Lond [B] 1957;146:439-459.

112 Messenger JB: Multimodal convergence and the regulation of motor programs in cephalopods; in Horn E (ed): Multimodal Convergences in Sensory System. Fortschritte der Zoologie. Stuttgart, Fisher, 1983, vol 28, pp 77-98.

113 Young JZ: Learning and discrimination in the octopus. Biol Rev 1961:36:43-60.

114 Messenger JB: Why octopuses? Have we learned anything from studying their brains? Sci Prog Oxf 1988;72:297-320.

115 Young JZ: The organization of a memory system. The Croonian Lecture. Proc R Soc [B] 1965;163:285-320.

116 Robertson JD, Bonaventura J, Kohm A: Nitric-oxide synthase inhibition blocks Octopus touch learning without producing sensory or motor dysfunction. Proc R Soc Lond Biol 1995;261:167-172.

117 Young JZ: The distributed tactile memory system in Octopus. Proc R Soc Lond [B] 1983: 218;135-176.

118 Graziadei P, Gagne HT: Sensory innervation in the rim of the octopus sucker. J Morphol 1976;150:639-679.

119 Young JZ: The nervous pathways for poisoning, eating and learning in Octopus. J Exp Biol 1965;43:581-593.

120 Allen A, Michels J, Young JZ: Possible interactions between visual and tactile memories in Octopus. Mar Behav Physiol 1986;12:8197.

121 Robertson JD: Cytochalasin-D blocks touch learning in Octopus vulgaris. Proc R Soc Lond Biol 1994;258:61-66.
122 Blokland A: Acetylcholine: A neurotransmitter for learning and memory. Brain Res Rev 1995;21:285-300.

123 Everitt BJ, Robbins TW: Central cholinergic systems and cognition. Ann Rev Psychol 1997;48:649-684.

124 Sarter M, Bruno JP: Cognitive functions of cortical acetylcholine: Towards a unifying hypothesis. Brain Res Rev 1997;23:28-46.

125 Barraco, DA and Eisenstein, EM: Effects of pre-training administration of scopolamine on learning and retention in the cockroach, P. americana. Pharmacol Biochem Behav 1984;20:479-481.

126 Gauthier M, Canolozano V, Zaoujal A, Richard D: Effects of intracranial injections of scopolamine on olfactory conditioning retrieval in the honeybee. Behav Brain Res 1994; 63:145-149.

127 Mpitsos GJ, Murray TF, Creech HC, Barker DL: Muscarinic antagonist enhances one-trial food-aversion learning in the mollusc Pleurobranchea. Brain Res Bull 1988;21:169-179.

128 Messenger JB: Neurotransmitters of cephalopods. Invert Neurosci 1996;2:95-114.

129 Bellanger C, Dauphin F, Belzunces LP, Chichery R: Parallel regional quantification of choline acetyltransferase and cholinesterase activity in the central nervous system of an invertebrate (Sepia officinalis). Brain Res Protocol 1998;3:68-75.

130 Halm MP, Chichery MP, Chichery R: The role of cholinergic networks of the anterior basal and inferior frontal lobes in the predatory behaviour of Sepia officinalis. Comp Biochem Physiol [A] 2002;132:267-274.

131 Fiorito G, Agnisola C, d'Addio M, Valanzano A, Calamandrei G: Scopolamine impairs memory recall in Octopus vulgaris. Neurosci Letts 1998;253:87-90.

132 Sumbre G, Gutfreund Y, Fiorito G, Flash T, Hochner B: Control of octopus arm extension by a peripheral motor program. Science 2001; 293:1845-1848.

133 Lucero MT, Chen NS: Characterization of voltage- and $\mathrm{Ca}^{2+}$-activated $\mathrm{K}^{+}$channels in squid olfactory receptor neurons. J Exp Biol 1997;200:1571-1586.

134 Budelmann BU, Young JZ: The oculomotor system of decapod cephalopods: Eye-muscles, eye muscle nerves, and the oculomotor neurons in the central-nervous-system. Phil Trans R Soc Lond [B] 1993;340:93-125. 